\title{
ALGUNAS CONSIDERACIONES CRÍTICAS SOBRE EL PROBLEMA DE LA MÍMESIS ARTÍSTICA EN ADORNO Y LUKÁCS
}

\author{
ALGUMAS CONSIDERAÇÕES CRÍSTICAS SOBRE O PROBLEMA DA MÍMESIS ARTÍTICA EM \\ ADORNO E LUKÁCS
}

Emiliano Orlante*

\begin{abstract}
RESUMEN
Este ensayo analiza una de las polémicas más trascendentales en el campo de la estética del siglo XX del denominado marxismo occidental: Adorno - Lukács. Si bien esta contienda ha sido tratada desde diversos enfoques teóricos y políticos, la crítica especializada ha desatendido los alcances de la categoría de mímesis dentro de esta confrontación filosófica. De hecho, la mayoría de los trabajos que abordan este problema estético toman por algo dado la relación de igualdad que Adorno hizo entre la teoría del reflejo de Lukács y el realismo socialista estalinista. Por esta razón, nuestra investigación se propone rastrear, en estos pensadores, el concepto de mímesis para luego analizarlo a partir de sus relaciones con otras categorías relevantes de la estética. En este derrotero, estudiaremos algunos conceptos de la estética de Heidelberg para cotejarlos con las categorías estéticas empleadas por Adorno. Una vez extraídas nuestras primeras ideas, pasaremos a indagar los fundamentos filosóficos y métodos de análisis de sus postulados estéticos. Finalmente, a la luz de nuestra pesquisa, intentaremos contribuir al debate con una nueva propuesta, que trate de dilucidar, a su vez, si las resonancias y desencuentros políticos, derivados de la equiparación entre teoría del reflejo y realismo socialista, pueden sostenerse desde el análisis filosófico de las categorías estéticas vinculadas con la mímesis.
\end{abstract}

PALABRAS CLAVE: Mímesis. Lukács. Adorno. Estética. Marxismo occidental.

\section{RESUMO}

Este ensaio analisa uma das polêmicas mais transcendentais no campo da estética do século XX do chamado marxismo ocidental: Adorno - Lukács. Embora essa disputa tenha sido tratada a partir de diferentes abordagens teóricas e políticas, a crítica especializada ignorou o escopo da categoria de mimese dentro desse confronto filosófico. Na verdade, a maioria das obras que lidam com esse problema estético, tomam como resolvida a relação de igualdade que Adorno fez entre a teoria da reflexão de Lukacs e o realismo socialista stalinista. Por essa razão, nossa pesquisa visa a traçar, nesses pensadores, o conceito de mímesis para analisá-lo a partir de suas relações com outras categorias relevantes da estética. Estudaremos alguns conceitos da estética de Heidelberg para compará-los com as categorias estéticas utilizadas por Adorno. Uma vez extraídas nossas primeiras ideias, passaremos a investigar os fundamentos filosóficos e os métodos de análise de seus postulados estéticos. Finalmente, à luz da nossa pesquisa, intentamos contribuir para esse debate com uma nova proposta que busca elucidar se as ressonâncias e divergências políticas, decorrentes da comparação entre a teoria de reflexão e realismo socialista, se sustentam a partir da análise filosófica das categorias estéticas ligadas à mimesis.

PALAVRAS-CHAVE: Mímesis. Lukács. Adorno. Estética. Marxismo occidental.

\footnotetext{
* Professor de Letras na Universidad de Buenos Aires (UBA) e na Universidad Nacional Arturo Jauretche (UNAJ). E-mail: e_orlante@yahoo.com.ar.
} 
[...] dada su forma tan extremadamente personal de llevar este tipo de polémicas, llegando incluso a arremeter contra la persona misma del atacado, de tal manera que a menudo resultaba velado el contenido principal de la polémica, [es decir] la profundidad teórico literaria de la misma (Lukács, 1970, p. 144).

La polémica entre estos filósofos aún presenta actualidad en el campo de la filosofía y de la estética, y ha sido abordada desde múltiples aspectos teóricos y, también, políticos. Sin embargo, la crítica no ha atendido demasiado los alcances del problema de la mímesis dentro de un marco de análisis de confrontación de ideas que fuera más allá del problema - ¿o procedimiento?- planteado por Adorno, el cual relaciona sin ambages la teoría del reflejo de Lukács con la polémica tendencia literaria del estalinismo, denominada realismo socialista. De este modo, y transitando un corpus teórico exento de acusaciones mutuas infundadas, o fundamentadas ad hoc, trataremos de analizar, del modo más objetivo posible, el problema de la mímesis, deslindando sus implicancias y relaciones con otras categorías de sus respectivas filosofías que puedan ayudar a esclarecer los abordajes metodológicos y las concepciones teóricas de estos dos filósofos del llamado marxismo occidental.

En este análisis, rastrearemos, dentro del corpus descrito en la bibliografía, la categoría de mímesis, tratando de comprender su conceptualización a partir de los distintos momentos teóricos en los que aparece, para luego aproximarnos, de manera crítica, a los problemas metodológicos y ontológicos que sustentan las distintas o, en algunos casos, similares concepciones acerca del hecho artístico de estos dos filósofos. Luego, y en la medida de lo posible, trataremos de intervenir críticamente en la polémica, procurando contribuir, de algún modo, con nuevos sentidos al análisis de esta problemática estética y filosófica. De acuerdo con este programa metodológico, y especificando parte del párrafo anterior, pensamos que, para una mejor problematización conceptual, el abordaje crítico se desarrolle, en principio, problematizando distintos temas referidos a la estética, en los cuales la categoría de mímesis ya dentro de un contexto crítico determinado, logre hacer emerger significados y evidenciar algún concepto formal que dé cuenta de las miradas del mundo que poseen dichos filósofos.

En este trabajo, optamos por esta organización, ya que esta categoría no está desarrollada del mismo modo por estos dos filósofos. En el caso de Lukács, la mímesis es un concepto central para la teoría del reflejo, que es la base de todo conocimiento científico, y por tal motivo, está desarrollada y abordada de un modo exhaustivo. Por otro lado, el autor de 
Teoría estética, al tratar la mímesis o el aspecto mimético, lo hace en relación a la construcción de la obra de arte. Para dejar clara una ostensible diferencia entre estos grandes filósofos del siglo XX, la categoría de mímesis, en Adorno, no tiene la misma relevancia e importancia teórica, en apariencia, que en la concepción lukácsiana. De hecho, para el filósofo alemán, la mímesis no sustenta el conocimiento objetivo, sino que es una categoría dentro de la práctica artística y tiene que ver con un momento previo a la expresión: la mímesis es la "mueca" (extraída de lo cotidiano) inobjetivable que, gracias al trabajo del artista, logra objetivarse. Sin embargo, él no desarrolla de modo más preciso dicha categoría. Entonces, ¿cómo el artista pudo dar forma a lo no objetivo?, ¿lo representó primero en la mente para luego concretarlo en el mundo empírico? Si fuera así, ¿hay, entonces, una teleología implícita en las teorizaciones adornianas? Preguntas como estas guiarán el trayecto de nuestro trabajo.

\section{EN UN INICIO, HEIDELBERG}

Al indagar y cotejar las contribuciones estéticas de ambos filósofos, hemos reparado en que algunos conceptos estéticos del joven Lukács de Heidelberg fueron posteriormente tomados y adecuados por Adorno a su filosofía del arte. En este sentido, la afirmación de Schwarzböck, acerca de que Adorno no cita ni menciona a los pensadores que contribuyeron, con sus teorías, en la fundamentación de algunos de sus postulados teóricos, en el caso de Lukács, se mantiene con gran firmeza.

Los años de Heidelberg fueron de gran trabajo intelectual para el joven filósofo húngaro, ya que procuró ordenar tanto sus ideas estéticas como éticas. En este período, Lukács desarrolla ciertos conceptos que tuvieron gran importancia e influencia en el campo estético y crítico del siglo XX. Además, estas categorías sugieren muchos puntos de contacto con las posteriores concepciones y formulaciones de Adorno. Del cotejo de estas primeras concepciones estéticas, encontramos estos tributos silenciados:

1) Lukács, por esos años, formula la idea de objetivación del espíritu; es decir, una vez producida la obra, esta pasa a ser valor para la humanidad, llevando el sello personal de su hacedor. El concepto de Adorno que podríamos relacionar con esta objetivación lukacsiana, es el de la cosificación del propio sujeto al producir la obra. Esto puede explicarse por la preeminencia del objeto que el autor de Actualidad en filosofía postula en toda su teoría. Según Adorno, el sujeto artístico se disuelve en la configuración de la obra. Y esta disolución es uno de los fundamentos de la objetivación de la obra de arte. 
2) El joven Lukács concibe a la obra de arte como una totalidad cerrada en sí. De acuerdo con esto, Adorno concibe a la obra de arte, parafraseando a Leibniz, como una "mónada sin ventanas” y, continúa, es gracias a esta cerrazón, y a su carácter inmanente, que el arte puede constituirse como crítica "muda" de la sociedad. Sin embargo, a la luz del trabajo de Tertulian (1986, p. 51), la comparación de la obra de arte con la "mónada sin ventanas" de Leibniz fue formulada primero por el joven Lukács en la Estética de Heidelberg.

3) La obra de arte, para Lukács, recupera el orden que la vida cotidiana burguesa no tiene. El arte se erige, ante el caos social, de un modo ordenado. Es más, esta es una de sus tesis de $E l$ alma y las formas: la oposición entre vida cotidiana (que se presenta como caótica) y forma (arte, como hecho ordenador) es central en este período. Por su parte, y siguiendo esta idea, Adorno concibe al arte con un doble carácter: fait social y autonomía. Este último aspecto es el que tercia en la configuración del arte como contrario a la sociedad. Entonces -y aquí está el acercamiento a la concepción lukácsiana-, cuando la sociedad se presenta como caótica y desordenada, el "arte verdadero" debe constituirse formalmente ordenado. Sin embargo, al ser esta teoría relativista y negativa, Adorno, también sostiene lo contrario; es decir, el "arte autónomo" puede constituirse formalmente fragmentado y caótico al ver que la sociedad se presenta ordenada y eficiente.

4) Otra de las ideas coincidentes entre ambos filósofos se vincula con la concepción de Lukács sobre el arte como realidad utópica. Del mismo modo, Adorno, siguiendo a $\mathrm{H}$. Cornelius, quien fuera uno de sus maestros, le otorga cierto carácter utópico al arte autónomo, más precisamente a la posibilidad que tiene éste de configurar, desde la forma, un orden completamente opuesto al de la sociedad mercantil.

5) Por último, el autor de Goethe y su época sostiene que el arte tiene una misión desfetichizante. A diferencia de los objetos convencionales del capitalismo, que se presentan desprovistos de sujetos, es decir, totalmente cosificados, los objetos artísticos, por el contrario, se encuentran cargados de "subjetividad". En Adorno, también, la desfetichización podría hallarse en la obra de arte, más precisamente en la idea de contenido de verdad. Este concepto se refiere al momento en el cual la obra de arte autónoma muestra formalmente las contradicciones sociales. El contenido de verdad, dentro de la filosofía del arte adorniana, a nuestro entender, sería el único momento en que la obra no se presenta como fetiche, ya que como contrapartida a este momento, la obra tiene, al mismo tiempo, un momento de falsedad; y éste es, siguiendo al Lukács de Historia y conciencia de clase, el carácter de circulación mercantil que posee la obra de arte en el capitalismo. En otros términos, su falsedad está en su 
valor de cambio. Pero, a diferencia del autor de La peculiaridad de lo estético, Adorno sostiene que solo la reflexión filosófica puede dilucidar el momento de verdad de la obra artística.

Más allá de que entre la Estética de Heidelberg y La ontología del ser social podemos encontrar un giro importante en el aspecto metodológico de Lukács, esta primera aproximación, a través de los conceptos originados en Heidelberg, trata de analizar, en principio, el sustrato común que aparece por debajo de las grandes discusiones. Lo que intentaremos hacer en los próximos apartados es analizar si este sustrato común se mantiene y si las discusiones, generalmente iniciadas por el filósofo alemán, podrían llegar a desvanecerse desde un riguroso análisis de los conceptos.

\section{PRIMERA APROXIMACIÓN AL PROBLEMA Y A SUS FUNDAMENTOS FILOSÓFICOS}

En los siguientes párrafos, haremos una escueta mención acerca de los términos generales del problema. Este relevamiento, si bien puede pecar de enciclopedista o descriptivo, creemos que es necesario para introducirnos en la problemática y en el ulterior análisis crítico del problema en cuestión. Luego, promediando el apartado, trataremos de dar cuenta, en forma sintética, de las principales tensiones filosóficas que existen entre estos dos pensadores. De este modo, y bajo estas distinciones dentro de sus fundamentos filosóficos, podremos acercarnos mejor a una comprensión general de sus determinaciones intelectuales y prácticas.

En "Lukács/Adorno - La reconciliación imposible", Tertulian ofrece un aspecto bastante esclarecedor para un primer acercamiento a la discusión del problema. Según este, el autor de Notas sobre literatura hubo mal interpretado la concepción lukácsiana de la teoría del arte, a la cual había catalogado de "materialismo vulgar" y de "reflejo de la realidad objetiva". En relación con ello, Adorno objetaba la estrecha vinculación entre la esfera artística y la realidad empírica que promovía el realismo socialista. Para el filósofo de Frankfurt, esta directa relación entre obra y vida degradaba la obra de arte, ya que el sujeto artístico, a través de la técnica y del dominio de los materiales, no mediaba entre estos dos ámbitos para la configuración de la obra de arte.

Por su parte, Lukács ya para entonces había producido un viraje fundamental en su concepción estética. En uno de sus trabajos sobre Lukács, Vedda (2006) coteja los dos 
períodos estéticos del autor de Problemas del realismo para luego analizar con precisión los cambios filosóficos más fundamentales que hizo gracias a la apropiación de la filosofía del joven Marx. Según este análisis, entre la Estética de Heidelberg y la Ontología del ser social podemos encontrar un giro importante en el aspecto metodológico de Lukács. En su juventud, el filósofo húngaro sostenía la idea de que el arte se contraponía a la cotidianidad, conllevando, esta idea, una postura epistemológica. En cambio, en su madurez, Lukács, por más que comparta aún esta idea propia de la autonomía del arte, profundiza esta característica para detenerse en el origen del mismo, entendiéndolo, ya desde una postura ontológica, como una nueva objetividad producida por el trabajo del hombre.

Por más que el autor de Historia y conciencia de clase, en su madurez, ya había comenzado una etapa ontológica en su pensamiento, concepciones estéticas de su juventud en lo referidas a la inmanencia artística se mantienen con vigor. Estas ideas, aún vigentes para el viejo Lukács, son desatendidas por Adorno, quien, apoyándose en el compromiso político del húngaro, relaciona casi ciega y directamente las ideas estéticas de este con la estética del realismo socialista.

Además de estas diferencias dentro del plano de la estética, podemos encontrar, como correlato, ostensibles diferencias en el seno de sus fundamentos filosóficos. En este sentido, aunque la enunciación del problema parezca una obviedad, nos ha parecido pertinente, a la luz de la crítica de la mímesis, dedicarnos someramente al planteo de este problema de base, dado que, si bien hay cuantiosos trabajos que ponen en evidencia la controversia que se dio dentro del plano de la estética y de la crítica literaria, no hemos hallado trabajos, a lo largo de toda la bibliografía consultada, que atendieran y cotejasen los principales puntos de tensión, que se encuentran en la base de la disputa dentro de la esfera estética, entre las concepciones filosóficas de estos dos exponentes del marxismo occidental.

En sus trabajos filosóficos, Adorno, para abrir el sistema dialéctico, que en Hegel se presenta como cerrado para poder constituir lo absoluto y necesario, comienza a concebirlo como lo que podría no haber ocurrido o tenido lugar, es decir, lo entiende en términos contingentes. La oposición al carácter necesario de la filosofía hegeliana hace que Adorno haga de la contingencia la base fundamental de su filosofía crítica. De este modo, la contingencia afecta tanto al pasado como al futuro, porque nunca nada fue necesario (SCHWARZBÖCK, 2008, p. 29).

Desde otra perspectiva, Lukács, siguiendo a Marx, concibe el desarrollo del género humano como un proceso histórico, en el cual la propia acción de los hombres tiene una 
relevancia que puede llegar a ser determinante dentro del mundo empírico. En este sentido, las circunstancias o contingencias, que para Adorno son el fundamento de su dialéctica, no son sino, para el filósofo de Budapest, formas aparentes del propio proceso histórico. En otros términos, mientras que el proceso repara en la esencia del mismo, en su carácter ontológico, las contingencias son meras formas de manifestación del fenómeno. En palabras del viejo Lukács:

En todos estos esfuerzos nuestros hay una gran tarea consistente en descubrir primero en el ámbito de la teoría que todas estas circunstancialidades y cosificaciones no son sino meras formas de presentarse ciertos procesos reale. (HOLZ; KOFLER; ABENDROTH, 1969, p. 158).

Siguiendo con el análisis, estas diferentes concepciones filosóficas mantienen, al mismo tiempo, distintas implicancias con respecto al llamado concepto de manipulación dentro del capitalismo tardío. Sobre este tema, la concepción adorniana presenta pocas alternativas de resistencia al mundo administrado. Ni la racionalidad para el cambio, que propone Marx, ni el conocimiento de los límites humanos, que promueve Freud, podrían revertir el estado de la cuestión de la sociedad contemporánea. Según Schwarzböck, el bloqueo al cambio de paradigma del autor de Consignas se encuentra en la radicalización de los problemas de la psicología freudiana y en su escéptica postura respecto al proceso de cambio, a través de algunos aspectos positivos de la ilustración, que propone Marx. De hecho, Adorno sólo encuentra resistencia dentro de los límites del arte autónomo y en la reflexión filosófica.

Sin embargo, el filósofo de Frankfurt concibe a la política como una actividad que podría indicar el momento propicio para una parcial emancipación de la humanidad. Decimos parcial, ya que Adorno, en sus escritos, nunca ha dado indicio de un utopismo que vaya más allá de la inmanencia de la obra de arte. Es más, de acuerdo con la cerrazón de la obra y su momento de verdad, el autor de Actualidad en la filosofía hace de la reflexión filosófica la única vía posible para dilucidar los momentos de verdad del arte autónomo. En esta tendencia, yendo más allá de la obra y a la luz de los sucesos ocurridos con el movimiento estudiantil alemán a fines del decenio de los ' $60,{ }^{1}$ Adorno convierte al filósofo en el exégeta de la

\footnotetext{
${ }^{1}$ Nos referimos, precisamente, a lo que sucedió con el movimiento estudiantil, tras la visita a Alemania del Sha de Persia en el verano de 1967. En la jornada de repudio por su visita, el estudiante Benno Ohnesorg muere asesinado de un disparo por la espalda hecho por un jefe policial. Adorno, acoplándose a la posición de Horkheimer, mantuvo una posición conservadora, y hasta reaccionaria, durante la conmoción política y la revuelta estudiantil.
} 
modernidad, ya que este, también a través de la reflexión filosófica, es el único que puede determinar si las condiciones históricas son las pertinentes para pasar a la praxis en los momentos de agitación política.

Haciendo una indagación acerca de esta preeminencia de la actividad reflexiva del filósofo en la teoría adorniana, pudimos encontrar su posible origen en la Poética de Aristóteles. En este libro, más precisamente en el capítulo IV, intitulado "Sobre el origen de la poesía y de la tragedia", el filósofo antiguo establece una distinción entre el hombre general y el filósofo en lo relativo al aprendizaje. Esta diferencia radica en que la capacidad de aprender del hombre general es más limitada, ya que el filósofo puede experimentar mayor placer al contemplar el arte, además de estar mejor preparado para interpretar una obra a través del análisis de su técnica.

La razón de ello es que el aprender nos brinda el más elevado de los placeres, y no solo a los filósofos, sino a los hombres en general, aunque en estos la capacidad para aprender sea más limitada. Por esta razón es que experimentamos placer al contemplar imágenes: aprendemos de ellas y podemos inferir qué representa cada cosa... En cambio, si no se ha visto anticipadamente el original, el placer no se deberá a la imitación en tanto tal, sino en razón de su ejecución [...]. (ARISTÓTELES, 2002, p. 39, subrayados nuestros).

En este sentido, podemos advertir cómo Adorno se apropia de esta distinción aristotélica, en la cual el filósofo se destaca por sobre el resto de los mortales, radicalizándola hasta su sistematización. De hecho, siguiendo la obra adorniana, lo que se desprende de sus teorizaciones es que la figura del filósofo es la más apropiada para interpretar los hechos artísticos y los momentos de la política, ya que este, gracias a su disposición para el análisis, puede reflexionar sobre la configuración y la técnica del arte autónomo, como así también sobre el escenario político de la modernidad.

Volviendo al eje del análisis, Lukács, por otro lado, al considerar como fundamento ontológico los procesos históricos de los hombres, estima a las circunstancias como cosificaciones propias de ese proceso. Es más, este sostiene que la manipulación, ejercida en el capitalismo desarrollado, impulsa, de modo insistente, a considerar a las circunstancias como una "fórmula última de existencia ontológica", en tanto que la verdadera forma de existencia es, para este, el proceso.

A partir de esta contundente diferencia conceptual, el autor de Sociología de la literatura puede recuperar a la actividad del hombre por antonomasia, el trabajo, como pilar fundamental para la intervención dentro de la realidad empírica, interpretándolo, al mismo 
tiempo, como principio originario del desarrollo humano. De este modo, al ser el fin último del trabajo una realización concreta, este tiene, a razón de lo expuesto, una implicancia real de cambio dentro de la realidad cotidiana.

Por ello, Lukács, sabiendo de los cada vez más desarrollados métodos de manipulación dentro del capitalismo tardío, estima que la posibilidad de cambio e intervención frente a la misma se constituye del mismo modo en que el hombre se despliega para producir una nueva objetividad. La constitución ontológica de la categoría del trabajo podría tomarse como la matriz que subyace en esta idea, el poder para transformar la dynamis [potencia] aristotélica en una realización concreta dentro de la realidad empírica.

Por el contrario, en la concepción del filósofo de Frankfurt, la manipulación desmedida en el mundo administrado deja a los hombres como autómatas frente al universo de las mercancías y de la ideología. Pero esta condena con la que Adorno, a través de sus reflexiones, estigmatiza a la humanidad es materialmente detectada dentro del proceso histórico por el filósofo de Budapest. Este, fiel al materialismo dialéctico, encuentra que parte de este pensamiento derrotista, recurrente en la mayoría del ambiente intelectual alemán, evolucionó a partir del fracasó de la Revolución de marzo de 1848 y promueve, al mismo tiempo, la actividad intelectual para la superación de este pensamiento. En palabras de Lukács:

\begin{abstract}
A mi juicio, la gran mayoría de la intelectualidad alemana no puede progresar, no ya en la cuestión de la manipulación, sino ni siquiera en la interpretación de la misma, por así decir, si no se efectúa esa superación del pasado; esto es, si los alemanes no se dan cuenta de que tienen que volver a concebir su evolución en términos diferentes. No quiero remontarme a las guerras de los campesinos, como en su día dijo Humboldt, pero, de todas formas, comenzaré por decir que en 1848 se evitó seguir el camino correcto. [...] esa ideología trágica no es invención de la escuela de Frankfurt, sino que surge de una singular disonancia en la evolución alemana, manifiesta ya después de 1848 (HOLZ; KOFLER; ABENDROTH, 1969, p. 125).
\end{abstract}

\title{
TRAMO FINAL: ADORNO, LUKÁCS Y LA MÍMESIS
}

Dentro de la Teoría estética, podemos encontrar fragmentos referidos a la categoría de la mímesis sin que respondan a una idea conceptual desarrollada en toda su rigurosidad. En cierta medida, estos fragmentos aportan datos teóricos que, con el debido cotejo, pueden contribuir con la reposición de una idea conceptual, un tanto más acabada, pero no por ello menos problemática. 
En esos apartados de la Teoría estética, Adorno aparta la mímesis de las prácticas mágicas, y la relaciona, ya en la modernidad, con la racionalidad. Si bien el filósofo alemán concede a la conducta mimética el abandono de la magia, su postura negativa ante el racionalismo y su afán por presentar una dialéctica abierta hacen que la mímesis tenga una configuración dialéctica dentro de su propio concepto: entre el regreso a la magia pura y el abandono de la imitación ante una racionalidad objetiva.

Esta tesis comparte no pocas apreciaciones con la teoría del reflejo artístico de Lukács; es más, desde un plano conceptual, podría decirse que comparten la misma idea. El autor de La peculiaridad de lo estético concibe al arte de modo distinto a la filosofía y a la ciencia y, al mismo tiempo, afín, en cierta forma, a la magia, al animismo y a la religión, ya que una plena concordancia con estas prácticas harían subordinar el hecho artístico a una realidad trascendente. Hasta aquí, podríamos establecer una coincidencia entre esta teoría y la tensión entre magia y racionalidad que Adorno le otorga al arte, y que hemos mencionado en el párrafo anterior.

Sin embargo, el filósofo húngaro le otorga al arte un carácter antropomórfico, es decir, los objetos representados se encuentran "colmados" de subjetividad. A partir de esta caracterización, podemos apreciar la importancia que Lukács le otorga a la intervención humana, es decir al trabajo artístico, entendido ontológicamente como la posición teleológica - sin una función práctica -, en la cual la concatenación de una serie causal evidencia el factor real y de desarrollo de la realidad material. Por su parte, Adorno trata de borrar, desde su teoría, las marcas subjetivas de la obra de arte, disolviendo al sujeto dentro de las configuraciones de la obra. Si bien Lukács acuerda con la objetivación del sujeto dentro de la obra, el autor de Dialéctica negativa radicaliza esta posición en pos de lo que él llama la preeminencia de objeto, ya que, este es el único medio que la obra tiene para llegar a la verdad que le está oculta al sujeto.

Siguiendo con la pista de la mímesis dentro de la sinuosa Teoría estética, dicha categoría es presentada en otro contexto teórico como la objetivación de la irracionalidad. En este sentido, inferimos - ya que Adorno no se explaya al respecto - que la conducta mimética tiene cierta apreciación positiva para el autor de Mínima moralia, ya que la mímesis puede hacer objetiva la irracionalidad, es decir, puede hacer que elementos irracionales, gracias a la mediación técnica, se infiltren dentro de la racionalidad, conformando una nueva objetividad, en este caso, un nuevo hecho artístico. En este sentido, la obra se constituye formalmente 
como una crítica al mundo racionalizado, dado que dentro de sus límites pueden configurarse elementos irracionales.

De modo llamativo, en el apartado de Teoría estética Mímesis de lo mortal y reconciliación, la categoría de mímesis, en cierto sentido, aparece casi con la misma idea, en lo concerniente a la producción de la obra de arte, que en Lukács, ya que esta categoría es el medio por el cual se produce una nueva objetividad a partir de la realidad cotidiana. En palabras de Adorno (1983, p. 178):

\footnotetext{
Las obras de arte son negativas a priori en virtud de la ley de su objetivación: matan lo que objetivan al arrancarlo de la inmediatez de su vida. Su propia vida se alimenta de muerte. Tenemos aquí el umbral cualitativo hacia lo moderno. Sus obras, por medio de la mímesis, se entregan a la cosificación, su principio de muerte.
}

Desde ya que esta cita no plasma de modo claro el proceso de gestación artística, pero lo que sí queda en evidencia es que el hecho artístico surge del mundo empírico, de una realidad objetiva determinada, $y$, a partir de esta, produce una nueva objetividad. Lo que, tal vez, opaca un poco su sentido, y al mismo tiempo arroja luz sobre el problema mimético, es el empleo de una metáfora oscura al hablar de la cosificación de la obra: se alimenta de la "muerte" de la realidad.

En este sentido, y siguiendo con la cita, Adorno equipara el mundo empírico con la nueva objetividad creada por el artista. De hecho, estaría trazando una analogía entre vida y arte. En este sentido, el filósofo alemán caería en el mismo equívoco que caería la teoría del reflejo, según su particular interpretación.

Pero, lo que el autor de Mínima moralia no parece comprender, de modo explícito, es que la nueva objetividad, según la teoría del reflejo, se reproduce según la específica capacidad de la mente humana y, por tal razón, no según la naturaleza de los objetos. Aquí, vemos que la teoría del reflejo, desde su método separa de modo tajante el mundo objetivo de la reproducción de este por parte de la mente humana primero y la concretización del fin después.

De esta manera, y a partir de esta observación crítica, las acusaciones de Adorno, acerca de que la teoría del reflejo concibe la relación entre el arte y lo empírico de una forma no mediada, caerían ante la análoga metáfora, en la cual equipara arte y vida. Y la falta de mediación entre el mundo objetivo y la nueva objetividad de la obra artística, con la que él acusa a la teoría del reflejo, estaría, en definitiva, arraigada en el seno de su propia teorización acerca de la mímesis, ya que la mediación del artista (labor medular en toda teoría de la 
autonomía) propiciaría la reconciliación entre arte (nueva vida) y mundo empírico (muerte objetiva).

Cabría destacar que este proceso de la creación de una nueva objetividad se logra, según la cita, a través de la mímesis. Sin embargo, aquí, el filósofo de Frankfurt no se manifiesta en forma explícita acerca de una reproducción basada en la colocación de una posición teleológica en la mente del hombre. Este proceso de conocimiento y creación está elidido en los fragmentos de la Teoría estética, pero deja abierta una brecha para el interrogante que emerge junto con la aparición de una obra de arte como nueva objetividad.

Asimismo, la cuestión de la finalidad aparece de modo particular en el filósofo alemán. Este reconoce el principio estético de finalidad sin fin que aparece en Kant, pero omite las implicancias conceptuales de la teoría del reflejo artístico al respecto. Lukács, que había tomado de Aristóteles la teoría del reflejo y la mímesis, establece una relación casi indisociable entre reflejo y posición teleológica; con el reflejo, la conciencia puede dar el primer paso en la fijación del fin a concretar. Al mismo tiempo, el filósofo húngaro ha destacado enfáticamente que en la esfera artística los hechos representados no están orientados a satisfacer ninguna necesidad práctica y, además, se ajustan a sus propios criterios de representación. Esta teoría dialéctica, en su esencia, y de fuerte base antropológica no se encuentra dentro del objeto de análisis adorniano. Es más, por momentos, Adorno parece aceptarla de modo implícito, ya que no entra en discusión con ella en ninguna parte de sus trabajos analizados. Su discusión solo se limita a equiparar de modo superficial la teoría del reflejo artístico con la vida empírica, como si entre estos dos aspectos del conocimiento no hubiera diferencia alguna.

Como hemos señalado, los conceptos vertidos por el autor de Consignas acerca de la mímesis dejan un claro significativo sobre la cuestión de la elaboración o creación de la nueva objetividad. Este vacío, que el filósofo húngaro lo disipa con el fin teleológico que se genera a partir del reflejo de la realidad para la concreción de una nueva objetividad, en apariencia, no es del interés de Adorno, ya que, al llegar el momento teórico de pasar a su análisis, el filósofo alemán responde invocando a la inmanencia del hecho artístico. Claro ejemplo de ello es su abordaje de la mencionada categoría de la teleología, que, con un procedimiento bastante hábil, Adorno la desliza hacia el interior de la obra, evitando, de este modo, problematizar con la historia de la filosofía desde Aristóteles y con el continuo vacío que deja en su teoría las nuevas objetivaciones. Finalmente, el desplazamiento de la teleología hacia la inmanencia de la obra termina mezclando, y luego disolviendo, la finalidad, que se da dentro 
del conocimiento humano, con el carácter enigmático de la obra. ${ }^{2} \mathrm{Y}$, en la concepción adorniana, el descifre del enigma sólo puede hacerlo, a través de la reflexión, el filósofo exégeta.

\section{BIBLIOGRAFÍA}

ADORNO, Theodor W. Consignas. Buenos Aires: Amorrortu editores, 1993.

ADORNO, Theodor W. ¿Es alegre el arte?. Gaceta Psicológica, n. 85 (1989), p.18-21.

ADORNO, Theodor W. Notas sobre literatura. Barcelona: Ediciones Ariel, 1969.

ADORNO, Theodor W. Teoría estética. Madrid: Orbis, 1983.

ADORNO, Theodor; HORKHEIMER, Max. Dialéctica del iluminismo. Buenos Aires: Editorial Sudamericana, 1969.

ARISTÓTELES. Poética. Buenos Aires: Quadrata, 2002.

HOLZ; KOFLER; ABENDROTH. Conversaciones con Lukács. Madrid: Alianza, 1969.

LÓPEZ SORIA, José Ignacio. De lo trágico a lo utópico. Sobre el primer Lukács. Caracas: Monte Ávila, 1978.

LUKÁSCS, György. Arte y verdad objetiva. In: Problemas del realismo. México: Fondo de Cultura Económica, 1966.

LUKÁSCS, György. Heinrich Heine como poeta nacional. In: Realistas alemanes del siglo XIX. Trad. de Jacobo Muñoz. Barcelona: Grijalbo, 1970, p. 135-166.

LUKÁSCS, György. El alma y las formas. Trad. De Manuel Sacristán. Barcelona: Grijalbo, 1985.

LUKÁSCS, György. Estética. La peculiaridad de lo estético. Trad. de Manuel Sacristán. Barcelona: Grijalbo, 1966.

LUKÁSCS, György. Historia y conciencia de clase. Trad. de Manuel Sacristán. Madrid: Sarpe, 1985.

LUKÁSCS, György. Introducción a los escritos estéticos de Marx y Engels. In: Sociología de la literatura. Trad. de Michael Faber-Kaiser. Barcelona: Península, 1989.

LUKÁSCS, György. Ontología del ser social: el trabajo. Compilado por Antonio Infranca y Miguel Vedda. Buenos Aires: Herramienta, 2004.

\footnotetext{
${ }^{2}$ Según Adorno, el carácter enigmático consiste en que las obras dicen algo y a la vez lo ocultan. A nuestro entender, el autor de Teoría estética termina otorgándole un carácter místico a esta categoría, ya que el filósofo es el único que puede dar cuenta de lo que las obras dicen en verdad.
} 
MARX, Karl; ENGELS, F. Escritos sobre arte y literatura. Introducción de Miguel Vedda, trad. de Fernanda Aren, Silvina Rotemberg y Miguel Vedda. Buenos Aires: Colihue, 2003.

MARX, Karl. Manuscritos económico-filosóficos de 1844. Introducció de Miguel Vedda, trad. de Fernanda Aren, Silvina Rotemberg y Miguel Vedda. Buenos Aires: Colihue, 2006.

SCHWARZBÖCK, Silvia. Adorno y lo político. Buenos Aires: Prometeo, 2008.

TERTULIAN, Nicolae. Lukács-Adorno: la reconciliazione impossibile. In: LOSURDO, D.; SALVUCCI, P.; SICHIROLLO, L. (eds.). Gyorgy Lukács nel centenario della nascita 1885-1985. Urbino: Quattro Venti [Istituto Italiano per gli Studi Filosofici/Universita degli Studi di Urbino], 1986, p. 49-67.

VEDDA, Miguel. György Lukács y la fundamentación ontológica de lo estético. In: La sugestión de lo concreto. Estudios sobre teoría literaria marxista. Buenos Aires: Gorla, 2006, p. $57-103$. 